\title{
Pleiotropic effect of chromosome 5A and the mvp mutation on the metabolite profile during cold acclimation and the vegetative/generative transition in wheat
}

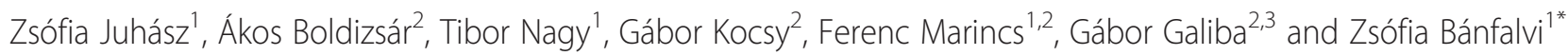

\begin{abstract}
Background: Wheat is the leading source of vegetable protein in the human diet, and metabolites are crucial for both plant development and human nutrition. The recent advances in metabolomics provided an opportunity to perform an untargeted metabolite analysis in this important crop.

Results: Wheat was characterised at the metabolite level during cold acclimation and transition from the vegetative to the generative phase. The relationship between these changes and chromosome 5A and the maintained vegetative phase (mvp) mutation was also investigated. Samples were taken from the shoots and crowns during four developmental stages: plants grown at $20 / 17^{\circ} \mathrm{C}$, after cold treatment but still during the vegetative phase, at the double ridge and during spikelet formation. The levels of 47 compounds were identified by gas chromatography-mass spectrometry, of which 38 were annotated. The cold treatment, in general, increased the concentrations of osmolites but not in all lines and not equally in the shoots and crowns. The accumulation of proline was not associated with the vernalisation process or with frost tolerance. The mvp mutation and chromosome 5A substitutions altered the amounts of several metabolites compared to those of the Tm and CS, respectively, during each developmental stage. The Ch5A substitution resulted in more substantial changes at the metabolite level than did the Tsp5A substitution. While Ch5A mainly influenced the sugar concentrations, Tsp5A altered the level of tricarboxylic acid cycle intermediates during the vegetative/generative transition. A much higher trehalose, proline, glutamine, asparagine, and unidentified $\mathrm{m} / \mathrm{z} 186$ content was detected in crowns than in shoots that may contribute to the frost tolerance of crowns.
\end{abstract}

Conclusions: Substantial influences of chromosome $5 \mathrm{~A}$ and the mvp mutation on metabolism during four different developmental stages were demonstrated. The distinct and overlapping accumulation patterns of metabolites suggest the complex genetic regulation of metabolism in the shoots and crowns.

Keywords: GC-MS, Metabolite profiling, Triticum aestivum, Triticum monococcum, Vernalisation

\section{Background}

Cereals are significant sources of food and animal feed, constituting more than $50 \%$ of the worldwide crop production. Globally, wheat is the leading source of vegetable protein in the human diet (http://faostat.fao.org/).

Triticum aestivum (common wheat or bread wheat) is a cultivated, allohexaploid wheat species with six sets of

\footnotetext{
*Correspondence: banfalvi@abc.hu

${ }^{1}$ NARIC Agricultural Biotechnology Institute, Szent-Györgyi A. u. 4, 2100 Gödölló, Hungary

Full list of author information is available at the end of the article
}

chromosomes (AA, BB, and DD), two sets from each of three different species [1]. Common wheat is an annual plant with several varieties of two classes: winter and spring wheat. Winter wheat is sown in the Northern Hemisphere from September to December, sprouts before freezing occurs and, as a result of shortening day lengths and decreasing temperatures, cold acclimates. This process is double faced: while it results in increased freezing tolerance (cold hardiness), it fulfils the vernalisation requirement [2]. Spring cereals are usually planted in spring and do not have a vernalisation requirement $[3,4]$.

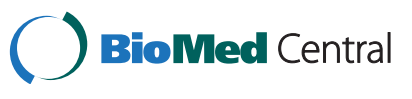

(c) 2015 Juhász et al.; licensee BioMed Central. This is an Open Access article distributed under the terms of the Creative Commons Attribution License (http://creativecommons.org/licenses/by/4.0), which permits unrestricted use, distribution, and reproduction in any medium, provided the original work is properly credited. The Creative Commons Public Domain Dedication waiver (http://creativecommons.org/publicdomain/zero/1.0/) applies to the data made available in this article unless otherwise stated. 
Natural variation in the vernalisation requirement in the temperate cereals is mainly associated with allelic differences in the VRN1, VRN2 and VRN3 vernalisation genes. VRN1 encodes a MADS-box transcription factor with high similarity to the Arabidopsis meristem identity genes APETALA1, CAULIFLOWER and FRUITFULL, which regulate the transition of the vegetative shoot apical meristem to the reproductive phase [5]. Winter genotypes that are maintained under continuous cold after an initial increase in freezing tolerance exhibit a progressive decrease in their cold acclimation ability after the shoot apical meristem advances to the double ridge stage [6-8]. The expression of the VRN1 gene gradually increased in winter genotypes during cold acclimation, while the cold-regulated genes $(C O R)$, which were positively associated with freezing tolerance, were down regulated [9]. Dhillon et al. [10] demonstrated a direct connection between the two processes.

T. monococcum (einkorn wheat) is one of the earliest cultivated forms of wheat and is a diploid species [11]. In this species, a radiation-induced deletion encompassing the VRN1 gene resulted in a mutant that was designated maintained vegetative phase ( $m v p)$, as homozygous $m v p$ / $m v p$ plants never flower, whereas plants carrying at least one functional VRN1 copy ( $M v p /-)$ exhibit normal flowering. The $M v p /$ - plants show reduced freezing tolerance and reduced transcript levels of several cold-induced genes relative to those of the deletion mutant $(m v p / m v p)$ plants $[10,12]$.

Because $T$. aestivum is hexaploid, its vital genes are replicated, allowing Sears [13] to develop a series of nullisomic lines (i.e., lines lacking one of the normal chromosomal pairs) from Chinese Spring (CS), a freezing-susceptible spring wheat. This genetic stock made possible the creation of single chromosome substitution lines. The genetic composition of the homologous alleles of VRN1 genes in CS is vrn-A1, vrn-B1 and Vrn-D1. Because CS carries the single dominant vernalisation-insensitive $V r n-D 1$ allele, CS is spring wheat $[14,15]$. In a study using a series of $5 \mathrm{~A}$ substitution lines in CS, the most vernalisation insensitive Vrn1 allele was found on chromosome $5 \mathrm{~A}$ of a $T$. spelta accession [16]. By replacing chromosome 5A of CS with the corresponding chromosome from a spring-type $T$. spelta accession [CS(Tsp5A)] conferred upon CS not only earlier ear-emergence [16] but also additional freezing sensitivity [14]. Cheyenne (Ch) is a winter wheat carrying recessive VRN1 alleles (vrn-A1, vrn-B1, and vrn-D1). Replacing chromosome $5 \mathrm{~A}$ of CS with the corresponding chromosome from $\mathrm{Ch},[\mathrm{CS}(\mathrm{Ch} 5 \mathrm{~A})]$ greatly increased the freezing tolerance of CS $[17,18]$. The freezing tolerance locus (FR2) on wheat 5A chromosomes contains a cluster of $C B F$ (C-repeat binding factor) genes [19]. The increased freezing tolerance of the $\operatorname{CS}(\mathrm{Ch} 5 \mathrm{~A})$ substitution line is due to the increased transcription level of winter wheat Ch $C B F$ genes in the CS genetic background [20].

The presence of $\mathrm{Ch}$ chromosome 5A in the CS background significantly elevated the sugar concentration, particularly that of sucrose and fructan, thereby resulting in increased osmotic potential and improved the freezing tolerance of the plants [21]. The accumulation of osmotic stress-induced free amino acids and polyamines is also regulated by chromosome 5A [22,23]. The role of chromosome 5A in the control of gene expression during cold hardening was demonstrated via a comparison of the cold-induced changes in the transcriptomes of CS and the two substitution lines. The genes that are affected by chromosome $5 \mathrm{~A}$ encoded proteins that are involved in transcriptional regulation, defence processes and carbohydrate metabolism [24].

Currently, metabolomics approaches have enabled the parallel assessment of the levels of a broad range of metabolites and have had great value in both phenotyping and diagnostic analyses in plants [25]. Based on our previous finding at the transcript profile level [24], we supposed that chromosome $5 \mathrm{~A}$ affects plants also at metabolite profile level. In this study, we used the tools of metabolomics to identify differences that are characteristic for cold acclimation and transition from the vegetative to the reproductive phases both in a $T$. monococcum accession KU 104-1 and T. aestivum ssp. ae. cv. Chinese Spring and investigated the involvement of chromosome $5 \mathrm{~A}$ and its VRN1 region in these two processes.

\section{Results}

\section{Experimental design}

A comparative metabolite analysis of the cultivated, moderately freezing-sensitive T. aestivum cv. Chinese Spring (CS) and its two chromosome 5A substitution lines, the freezing-tolerant $\mathrm{CS}(\mathrm{Ch} 5 \mathrm{~A})$ and the freezing-sensitive CS (Tsp5A), together with T. monococcum (Tm) and its mvp mutant was designed. The putative homozygous $m v p$ mutant lines were selected by genotyping because they could not be propagated due to the lack of flowering, and their phenotype was not different from that of wild type and heterozygous plants at the seedling stage. The homozygous mvp mutants were assorted by PCR, in which the primers were designed to amplify the missing VRN1 gene; consequently, no amplicons could be detected.

Metabolite profiling was performed on soil-grown plants in four different stages: (1) samples were collected before cold treatment from nine plants in three parallels from 21-day-old plants that were grown at $20 / 17^{\circ} \mathrm{C}$ (control, C) with the exception of CS(Tsp5A) because this genotype developed faster than did the others [16]; therefore samples from this line were collected at day $14^{\text {th }}$; (2) after 10 (Tm and $m v p$ ) and 14 days (CS lines) 
of cold treatment at $3^{\circ} \mathrm{C}$ in vegetative phase (Co); (3) in double ridge stages (Dr); and (4) when the spikelets (Sp) formed (Figure 1). The entire experiment was repeated three times. The plants with the CS, CS(Ch5A) and CS (Tsp5A) genotypes reached the Dr stage after $71 \pm 7,80 \pm$ 7 and $49 \pm 9$ days and the Sp phase after $90 \pm 7,95 \pm 7$ and $68 \pm 7$ days from germination, respectively. From the Tm and $m v p$ plants, Dr and Sp samples were collected after $42 \pm 7$ and $73 \pm 7$ days, even though in the case of $m v p$ plants, no phenotypic alteration of the apices occurred (Figure 1). Because it was clear that cold-responsive genes are differentially expressed between different tissues [26], both the shoots and crowns were investigated. Given the documented response of WCS19, COR14b and P5CS genes to abiotic stresses $[10,27,28]$ we have chosen these genes as molecular indicators of the cold treatment. Figure 2 shows that, in general, the cold upregulated the expression of all three tested genes, however, with different extents in different lines, organs and developmental phases. The level of WCS19 and COR14b expression, for example, was much higher in shoots than in crowns and was limited to the vegetative stage in shoots of CS lines. The $m v p$ mutation caused the up-regulation of all three genes in shoots during the cold treatment. The level of WCS19 and COR14b expression was also higher in $m v p$ than in Tm crowns during the entire growth phase. This is in line with a recent observation that the $m v p$ mutation reveals important changes in global gene expression [29].

\section{Identification of metabolites by gas chromatography- mass spectrometry (GC-MS)}

The polar primary metabolite composition of the collected shoot and crown samples was analysed by GCMS. The data were obtained from three replicate experiments except for the $m v p$ crowns, from which only two biological repeats were analysed in the $\mathrm{C}$ and Co stages. In total, 354 datasets were generated. In summary, the levels of 47 compounds were measured. The main classes of detected compounds included amino acids, organic acids, sugars and sugar alcohols. In addition to the 38 identified components, nine unidentified peaks were detected in various samples (Table 1 and Additional files $1,2,3,4,5$ and 6). A simplified scheme of the biosynthesis of the identified primary metabolites is presented in Figure 3.

Significant differences in the primary metabolite composition between the different developmental phases were determined by a one-way MANOVA. The means of three parallels in each experiment were calculated from the control and samples representing the different developmental phases, and the ratios of the means were determined. Compounds showing the same tendency of changes between the control and samples of different

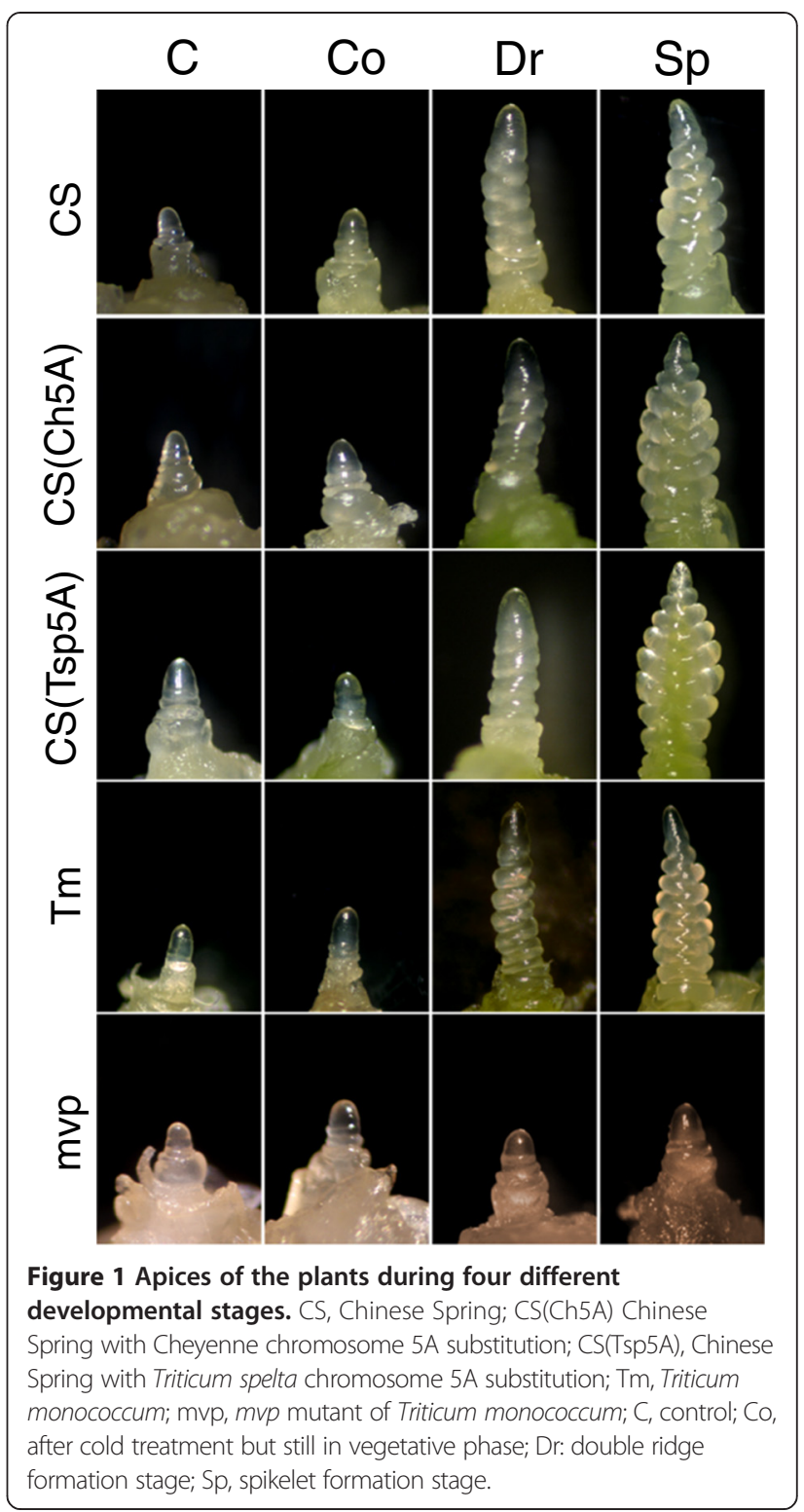

developmental phases in all three of the consecutive experiments were included into the heat-maps (Figures 4, 5 and 6). In case of $m v p$ crowns, from which samples could be collected only in two experiments, the means of the two data sets were used as a third data set.

\section{Metabolite changes that were related to developmental phases}

In general, both in the shoots and crowns, the cold increased the amounts of primary metabolites (Figure 4A and B). Except for the CS(Ch5A) shoots, a significant increase in the proline concentration was observed in all of the samples. Characteristic increases were also detected in the fructose, trehalose, raffinose, maltose, turanose, sucrose, glucose, galactinol, GABA, glutamine and asparagine contents as well as in the concentration of 


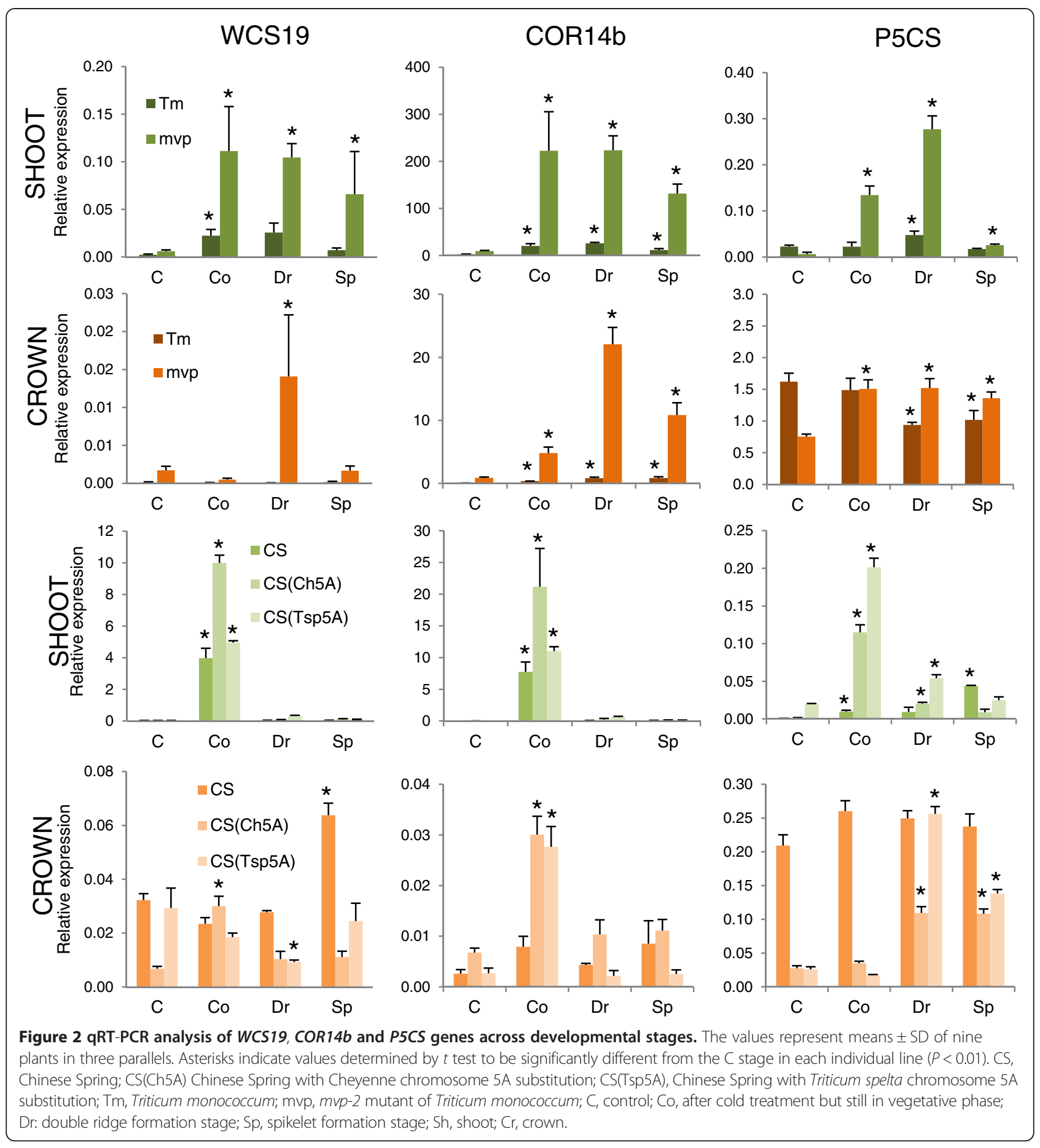

two unidentified compounds with $m / z 186$ and 597, albeit not in all lines and tissues. In contrast, except for $\mathrm{Tm}$, a decrease in the inositol content was detected in all the cold-treated shoot samples.

No compound with the same tendency of changes by double ridge (Dr) formation compared to the Co stage in the five wheat genotypes was identified. Broadly, however, except for the Tm crowns, the majority of these changes were reductions (Figure 4A). Compared to the $\mathrm{C}$ stage, however, several compounds, and especially those induced by cold, were present in higher amounts in each genotype and tissue (Figure 4B).

The spikelet formation, with a few exceptions, was characterised by decreases in the metabolite concentrations, especially in the crowns, where almost all of the detected changes were negative compared to the 
Table 1 Compounds detected in wheat samples by GC-MS analysis

\begin{tabular}{|c|c|}
\hline $\begin{array}{l}\text { Compound } \\
\text { class }\end{array}$ & Metabolites \\
\hline Amino acid $^{a}$ & $\begin{array}{l}\text { B-alanine, } y \text {-aminobutyric acid, asparagine, aspartic acid, glutamic acid, glutamine, glycine, isoleucine, 5-oxoproline }{ }^{b} \text {, phenylalanine, } \\
\text { proline, serine, threonine, tryptophan }\end{array}$ \\
\hline Sugar $^{\mathrm{a}}$ & fructose, galactose, glucose, maltose, mannose, ribose, raffinose, sucrose, trehalose, turanose \\
\hline Organic acid & cis-aconitic acid, cinnamic acid, citric/ isocitric acid, galactaric acid, glyceric acid, malic acid, succinic acid, threonic acid \\
\hline Sugar alcohol ${ }^{\mathrm{b}}$ & galactinol, inositol, sorbitol \\
\hline Fatty acid & palmitic acid, stearic acid, a-linolenic acid \\
\hline Unidentified & $\mathrm{m} / \mathrm{z}$ 116, $\mathrm{m} / \mathrm{z} 245, \mathrm{~m} / \mathrm{z}$ 160, m/z 234, m/z 186, m/z 204,205, m/z 204,191, m/z 387,299,357, m/z 597 \\
\hline
\end{tabular}

${ }^{a}$ With the exception of 5-oxoproline, identification of amino acids and sugars was based on authentic standards.

${ }^{b}$ Organic acids, sugar alcohols, fatty acids and 5-oxoproline were identified by searching the NIST 11 mass spectral database.

previous developmental stage (Figure 4A). Nevertheless, compared to the $\mathrm{C}$ stage, concentration of the coldinduced metabolites was still relatively high (Figure 4B).

\section{Metabolite changes that were related to the $m v p$} mutation and chromosome $5 \mathrm{~A}$

Substantial differences $(\log 2>1$ or $\log 2<-1)$ between $\mathrm{Tm}$ and $m v p$ were detected in most of the stages in both the shoots and crowns (Figure 5). For example, much more glycine was detected in $m v p$ than in Tm crowns in all stages and much more trehalose was detected in $m v p$ than in Tm shoots in C, Co and Dr stages. The $m v p$ mutation also increased the turanose content in $C$, the gluconic acid content in $\mathrm{Co}$, and the galactaric acid concentration in Co and Dr stages. The amount of the unidentified compound $m / z 234$ was also much higher in three out of eight different $m v p$ than in Tm samples. Nevertheless, based on a pairwise correlation analysis majority of the metabolites coordinately changed during development in Tm and $m v p$ (Additional file 7).

The substitution of chromosome $5 \mathrm{~A}$ in CS by either Ch5A or Tsp5A resulted in substantial differences in the metabolite levels during each stage (Figure 4A). For example, the concentrations of 12 metabolites decreased in

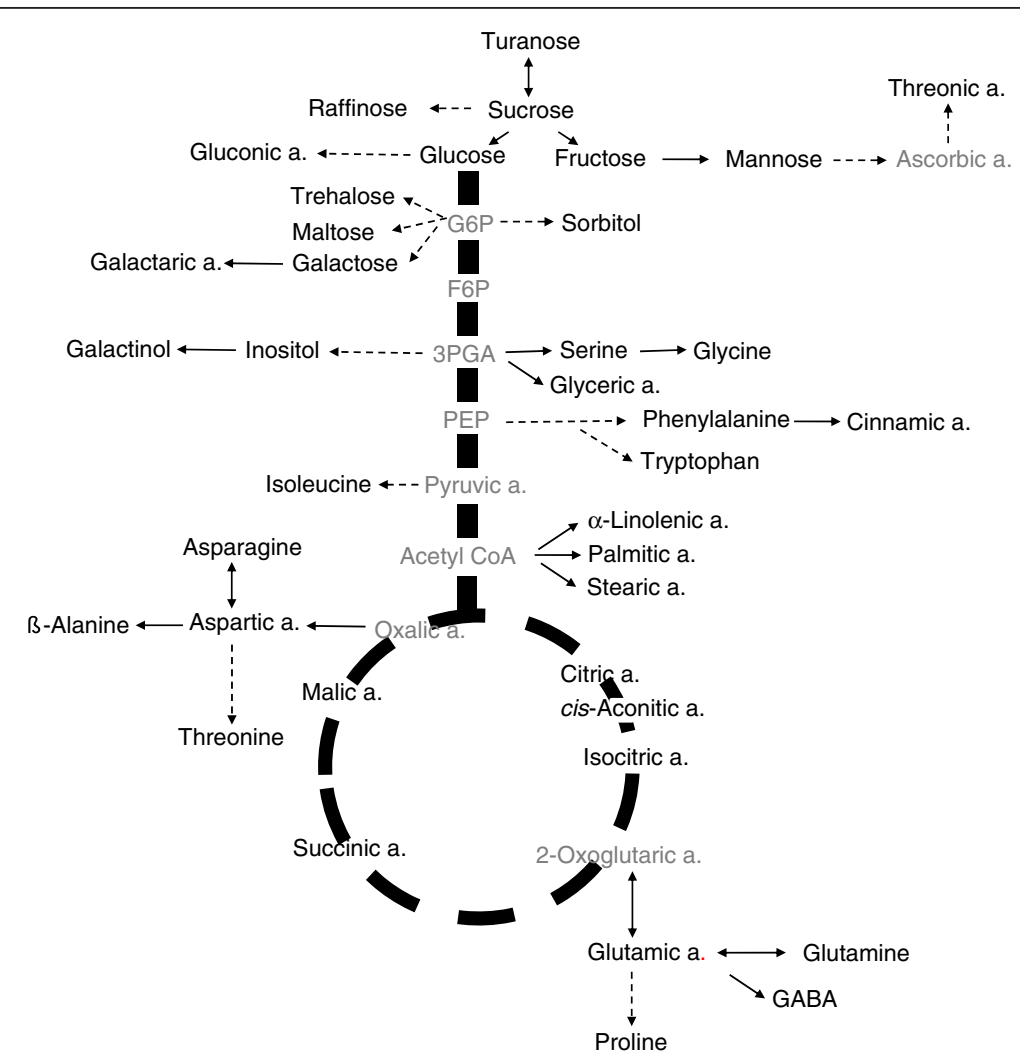

Figure 3 Simplified scheme of primary metabolite synthesis. The black letters depict the compounds that were detected, while grey letters depict the compounds that were not detected in the pathway. 


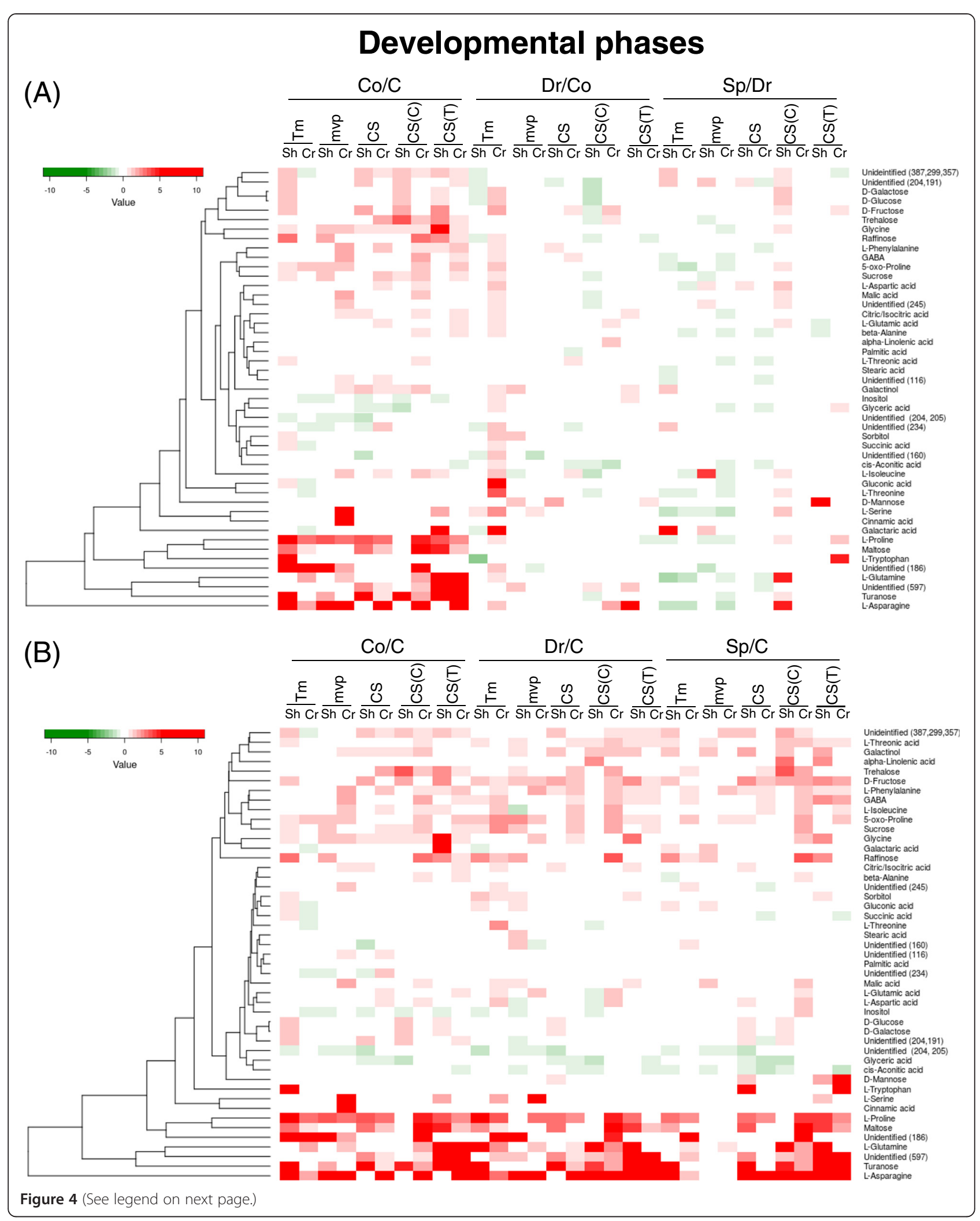


(See figure on previous page.)

Figure 4 Clustered heat-map of the metabolite changes related to developmental phases. The data were derived from three independent experiments. In each experiment, the samples were collected from a group of nine plants in three replicates except for the mvp crowns during the $C$ and Co stages, in which the samples could be collected only in two experiments. Only those compounds that showed significant changes (one-way MANOVA, $P<0.05)$ between the control and cold-treated samples $(\mathrm{Co} / \mathrm{C})$, cold-treated samples in the vegetative and double ridge formation stages ( $\mathrm{Dr} / \mathrm{Co}$ ) and double ridge formation via spikelet formation stages (Sp/Dr) in all of the experiments are included in the heat-map. The red colour depicts increases, while the green colour depicts decreases from one stage to another (A) and from a given stage to the control stage (B) in concentrations of the compounds that are listed in the figure. The scale is in log2. 5-Oxo-proline was derived from glutamic acid during the methoximation step. CS, Chinese Spring; CS(C) Chinese Spring with Cheyenne chromosome 5A substitution; CS(T), Chinese Spring with Triticum spelta chromosome 5A substitution; Tm, Triticum monococcum; mvp, mvp-2 mutant of Triticum monococcum; C, control; Co, after cold treatment but still in vegetative phase; Dr: double ridge formation stage; Sp, spikelet formation stage.

CS(Ch5A) but not in the CS shoots during the double ridge formation. Seven of these metabolites were sugars, i. e., galactose, glucose, fructose, trehalose, raffinose, sucrose and turanose. During spikelet formation, changes in the metabolite content were very different in the CS, CS (Ch5A) and CS(Tsp5A) in both the shoots and crowns. The pairwise correlation analysis showed that the substitution of chromosome 5A of CS by Ch5A resulted in more changes at the metabolite level than did that by Tsp5 A (Additional file 7), and while Ch5A influenced mainly the sugar concentrations, Tsp5A altered the level of TCAcycle intermediates (Additional file 8).

Chromosome 5A substitution resulted in elevation of metabolite concentration both in shoots and crowns of the CS line (Figure 5). Ch5A highly increased the amount of unidentified $m / z 186$, glutamine, trehalose and $\alpha$ - linolenic acid in certain tissues and stages. Genotypes CS, CS(Ch5A) and CS(Tsp5A) differ in frost sensitivity. Correlation of metabolite concentrations with the frost tolerance of the lines was investigated. Out of the cold-induced compounds, higher amount of glucose, trehalose, turanose, galactinol, and unidentified $\mathrm{m} / z 186$ were detected in the frost tolerant $\mathrm{CS}(\mathrm{Ch} 5 \mathrm{~A})$, but not in the most freezing sensitive $\mathrm{CS}(\mathrm{Ch} 5 \mathrm{~A})$, than in the shoots or crowns of the CS line with moderate freezing sensitivity. Thus we concluded that these compounds may contribute to the frost tolerance of the $\mathrm{CS}(\mathrm{Ch} 5 \mathrm{~A})$ line.

As expected, the largest differences were detected between the two Triticum species, T. monococcum and T. aestivum (Additional file 7). Concentration of most of the metabolites was lower in CS than in Tm, except of trehalose and glycine, which were present in much higher

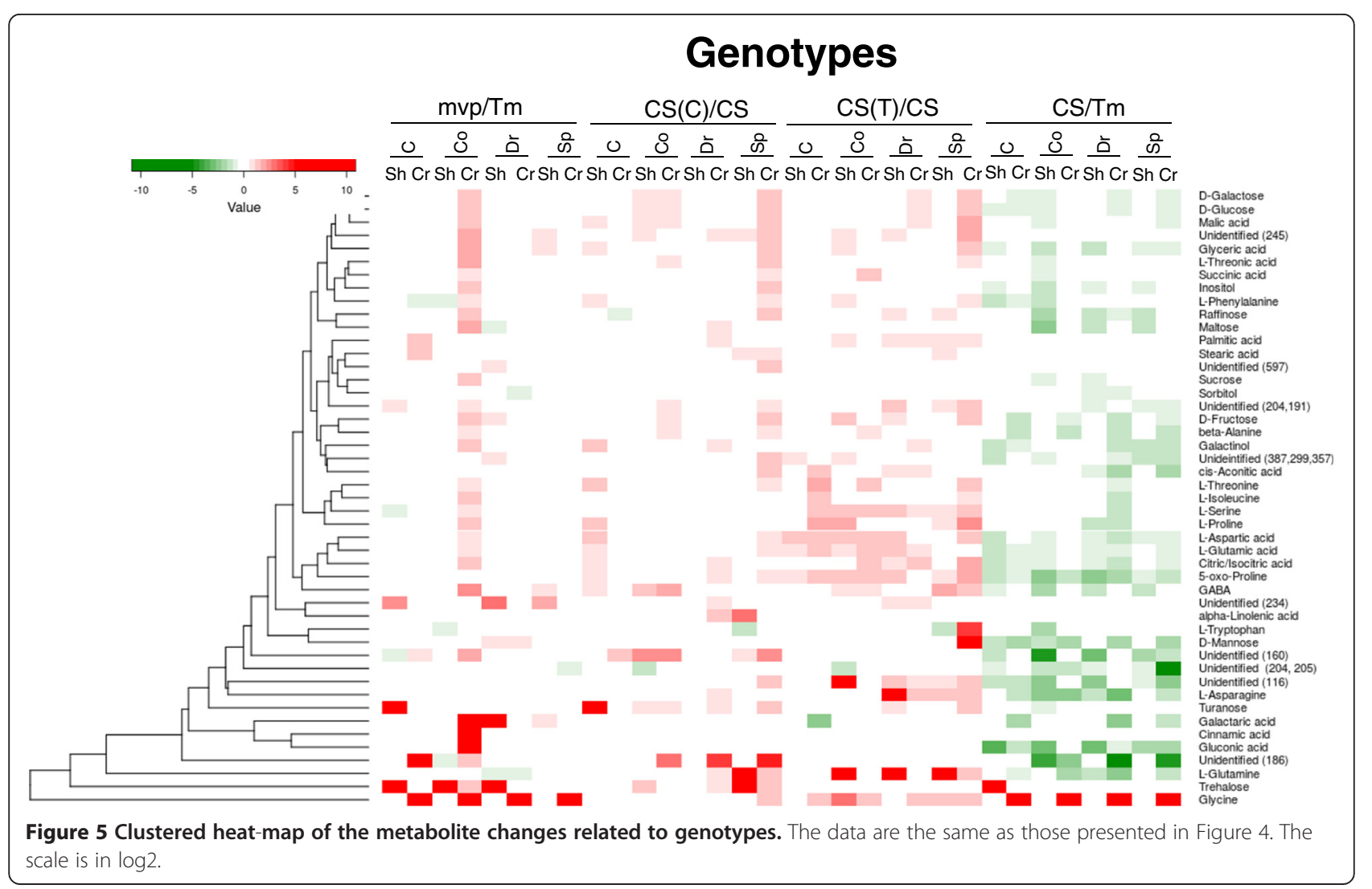




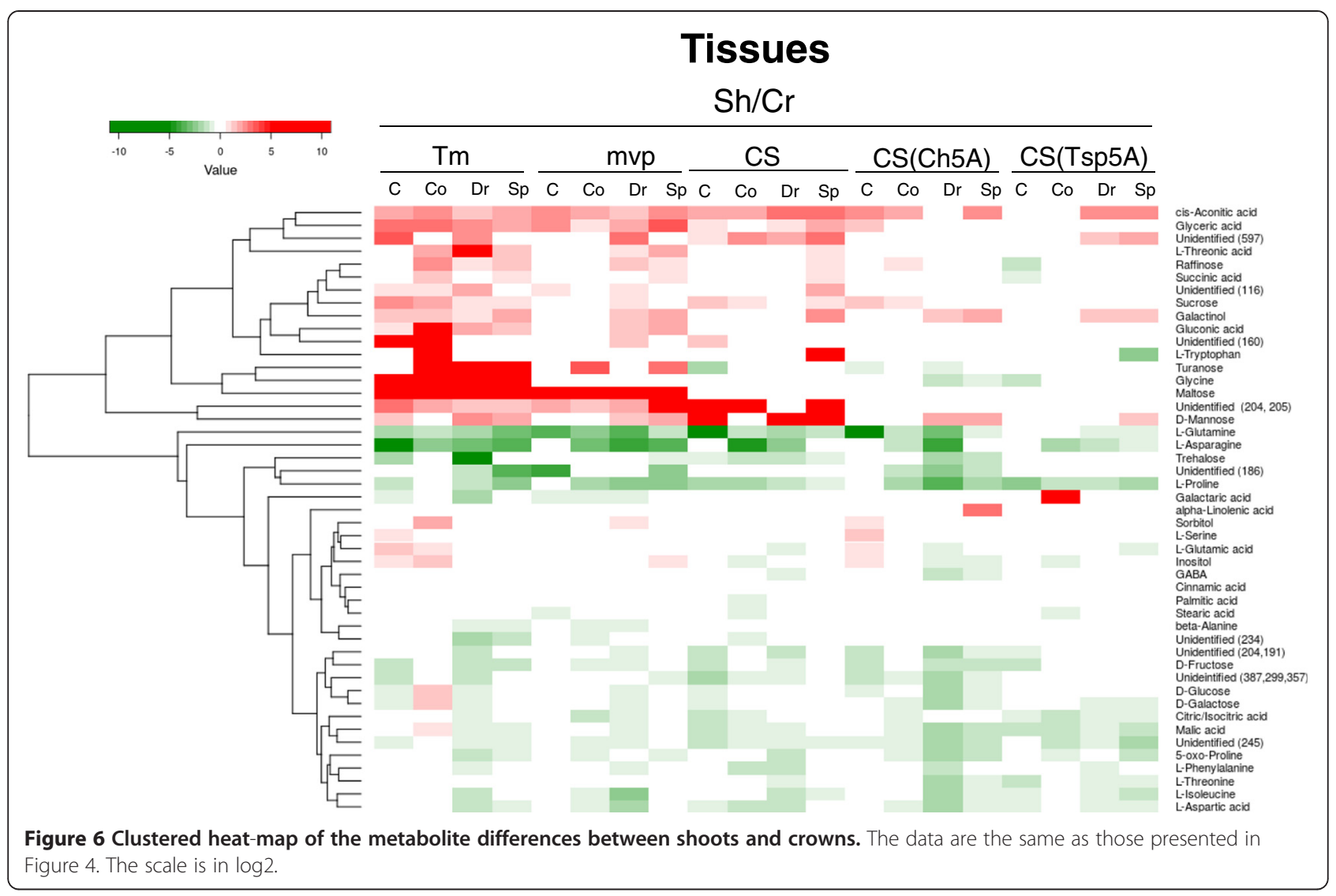

amounts in $\mathrm{Tm}$ shoots in $\mathrm{C}$ stage and in crowns during the whole life cycle, respectively (Figure 5).

\section{Differences in metabolite composition of shoots and crowns}

Ganeshan et al. [26] reported that COR genes are differentially expressed in leaf and crown tissues of wheat during an extended low temperature acclimation regimen. Thus we supposed that there are characteristic differences also in the metabolite composition of shoots and crowns. Figure 6 shows that there are really substantial differences in concentration of certain compounds and these differences are bigger in T. monococcum than in T. aestivum. The concentration of maltose is much higher in Tm shoots than in crowns in each developmental stage and this is not influenced by the $m v p$ mutation. In general, the level of cis-aconitic acid and glyceric acid is higher, while the level of glutamine, asparagine, proline, trehalose and unidentified $\mathrm{m} / z 186$ is lower in shoots than in crowns.

\section{Discussion}

Under cold stress conditions, plants accumulate compatible solutes, such as GABA, galactinol, maltose, proline, raffinose, sucrose and trehalose [30]. The results of this study demonstrate that the levels of all these metabolites increased in response to the cold treatment but not in all of the lines and not equally in the shoots and crowns (Figure 4). The most general increase was detected in the proline concentration as, except for the $\mathrm{CS}(\mathrm{Ch} 5 \mathrm{~A})$ shoots, this compound accumulated in both the shoots and crowns of each line in all three of the experiments. $M v p$ is a vernalisation mutant of $\mathrm{Tm}$, while CS, CS $(\mathrm{Ch} 5 \mathrm{~A})$ and CS(Tsp5A) differ in frost sensitivity. We found no association between the accumulation of proline and the vernalisation or freezing tolerance. Although a large body of data suggests a positive correlation between proline accumulation and plant stress tolerance [31], negative examples also exist. No correlation could be established, for example, between variations in the proline pool during cold exposure and the level of freezing tolerance for Arabidopsis and Thellungiella sp. [32]. The annual temperate wild grass Brachypodium is a model to study the response of temperate cereals to their environment. Although exposure to cold temperatures triggers the accumulation of proline in Brachypodium, the size of the proline pool of a given accession cannot be used to accurately predict its freezing tolerance behaviour [33]. Comparing three wheat cultivars with different freezing tolerances, the proline content increased in all of the cultivars after one week of cold acclimation, but a prolonged cold acclimation resulted in different profiles: no further increase occurred in 
the most sensitive cultivar, while an additional increase occurred in the other two cultivars [34]. We analysed the metabolite composition of the shoots and crowns after different durations of cold treatment; however, we detected a slight increase in the proline content compared to the previous stage only in the $\mathrm{Tm}$ crowns at double ridge formation and in the CS(Ch5A) and CS(Tsp5A) shoots when the spikelets were formed (Figure 4A). Thus, even the time course of proline content did not show a correlation with the freezing tolerance of the wheat genotypes in our experiment.

In plants, proline is synthesized mainly from glutamate, which is reduced to glutamate-semialdehyde by the pyrroline-5-carboxylate synthetase (P5CS) [31]. We have tested the level of P5CS expression and found that the cold up-regulated it in each line, both in shoots and crowns, however, with different extents and in different stages (Figure 2). The level of P5CS expression did not correlate with the proline concentration (Figures 4, 5 and 6) suggesting that, like in other plant species [31], the proline concentration is regulated by the interplay of biosynthesis, degradation and transport processes also in wheat.

The existence of positive correlations between the level of freezing tolerance of cereals and their capacities to accumulate water-soluble carbohydrates including sucrose and glucose was also previously observed [21,35-37]. The observed changes in the metabolite levels in these cases may derive from the activation of the related genes which was observed in a previous study investigating the transcriptome of the cold-treated CS and the substitution lines [24]. The transcript level of the genes encoding sucrose synthase 1 (gb|AL506883), sucrose synthase 2 (gb|BQ6 63764), and $\beta$-glucosidase (gb|BQ659818) was increased by cold treatment in the shoots and a corresponding alteration was shown in sucrose and glucose levels in the present study (Figure 4). In addition, similarly to the amount of the glucose (Figure 5), the transcription of the $\beta$-glucosidase gene was also greater in $\mathrm{CS}(\mathrm{Ch} 5 \mathrm{~A})$ than in CS and CS(Tsp5A) [24].

Turanose is an analogue of sucrose that was previously described as a sugar and that is not synthesised or metabolised by higher plants; however, turanose elicits responses that are distinctly different from those of metabolisable sugars and that are perceived as stress-related stimuli [38]. Recently, however, turanose was detected in red-ripening strawberry fruits, tobacco leaves, the roots of herbal plants and Agrostis grass species, mandarin fruits, and the leaves and roots of barley [39-42]. Even the accumulation of turanose in barley upon salt stress was observed [43]. Based on a comparison with an authentic standard we detected turanose in the CS lines with an increasing concentration upon cold treatment (Figure 4). Nevertheless, the function of turanose in wheat calls for future research.
Our results show that, with the exception of the Tm crowns, in general, the concentrations of primary metabolites are lower both in the shoots and crowns upon the transition from the vegetative to reproductive phase than in the vegetative phase after cold treatment. The detected negative changes at the metabolite level (Figure $4 \mathrm{~A}$ ) coincide with the down-regulation of the cold regulated $C O R$ genes, which are positively associated with freezing tolerance [9]. One explanation for the negative changes in the metabolite concentrations might be the acclimatisation of plants to the cold environment. Another explanation might be the use of primary metabolites for flower formation. However, at the time of spikelet formation, negative changes in the concentrations of several metabolites were detected in the Tm as well as in the never-flowering $m v p$ plants (Figure 4A), suggesting that the detected metabolites are used for vegetative growth rather than for spikelet formation. Nevertheless, majority of the cold-induced metabolites were present in higher concentrations during the transition from the vegetative to generative phase than in the control stage (Figure 4B).

The $m v p$ mutation was generated by a nitrogen ion beam, and the deletion in this mutant encompasses the complete VRN1 gene and other closely linked genes [44]. Metabolite profiling detected several differences in the metabolite composition of the Tm and $m v p$ shoots and crowns at each developmental stage (Figure 5), which is in line with the influence of the $m v p$ mutation on global gene expression [29], including the expression of WCS19, COR14b and P5CS genes (Figure 3). Because VRN1 encodes a MADS-box transcription factor [5], these differences may be explained by the pleiotropic effect of the genes that are regulated by VRN1. It is also possible that the genes that are closely linked to VRN1 are implicated in plant metabolism.

The influence of chromosome 5A, carrying the VRN1 gene, on metabolism was further supported by the large number of differences that were detected between the metabolite contents of the CS, CS(Ch5A) and CS(Tsp5A) lines (Figure 5). Substitution of chromosome 5A of CS by Ch5A resulted in more changes at the metabolite level than did that by Tsp5A, and while Ch5A influenced mainly the sugar concentrations, Tsp5A altered the level of TCA-cycle intermediates (Additional files 7 and 8).

Large number of differences was detected between the metabolite composition of shoots and crowns (Figure 6). The crown is the most freeze-resistant part of the plant [45]. When the crown meristematic tissue is destroyed by freezing, the plants are unable to resume growth in the spring [46]. We found a much higher glutamine, asparagine, trehalose, proline and unidentified $\mathrm{m} / z 186$ content in crowns than in shoots that may contribute to the frost tolerance of crowns. 


\section{Conclusions}

At the metabolite level, the differential accumulation of osmotically active solutes that were induced by cold treatment was observed in the shoots and crowns of five wheat genotypes. However, while the pool size of glucose, trehalose, turanose, galactinol and unidentified $\mathrm{m} / \mathrm{z}$ 186 correlated with the freezing tolerance of $T$. aestivum Chinese Spring and its two chromosome 5A substitution lines, the proline content did not. The $m v p$ mutation, encompassing the complete VRN1 gene and several closely linked genes, resulted in several differences in the metabolite composition compared to that of the wild type $T$. monococcum, which might be explained by the pleiotropic effect of the genes that are regulated by the MADS-box transcription factor VRN1. The transition from the vegetative to generative phase reduced the level of several metabolites in the shoots and crowns. An interesting difference was observed between the two Chinese Spring substitution lines with different freezing tolerances: while the Cheyenne chromosome 5A influenced mainly the sugar concentrations, the T. spelta chromosome $5 \mathrm{~A}$ altered mostly the level of TCA-cycle intermediates during the vegetative/generative transition. Experiments with more varieties would result in a better dissection and, most likely, a generalisation of this interesting finding related to chromosome 5A. A much higher trehalose, proline, glutamine, asparagine and unidentified $\mathrm{m} / \mathrm{z} 186$ content was detected in crowns than in shoots that may contribute to the frost tolerance of crowns. Since the concentration of the compound with $\mathrm{m} / z 186$ is associated with frost tolerance identification of this compound would help to understand the mechanism of cold acclimation.

\section{Methods}

\section{Plant materials}

A specific genetic system consisting of the moderately freezing-sensitive Triticum aestivum ssp. aestivum cv. Chinese Spring (CS) wheat variety and two chromosome $5 \mathrm{~A}$ substitution lines, the freezing-tolerant Chinese Spring (Triticum ae. ssp. ae. cv. Cheyenne 5A) [CS(Ch5A)] and the freezing-sensitive Chinese Spring (Triticum ae. ssp. spelta 5A) [CS(Tsp5A)], were used in the experiments [47-49]. In addition, Triticum monococcum KU 104-1 strain and its $m v p-2$ mutant that remains indefinitely in the vegetative state were analysed in this study. The mutant was generated by ion beam radiation and has a large deletion that includes VRN1 [12] and several flanking genes [44]. No phenotypical differences in shoots and crowns of the Tm and $m v p$ mutant and those of the CS and its chromosome $5 \mathrm{~A}$ substitution lines were detected $[12,49]$.

\section{Plant growth conditions}

After germination for 6 days $\left(1\right.$ day at $22^{\circ} \mathrm{C}, 3$ days at $4^{\circ} \mathrm{C}$, and 2 days at $22^{\circ} \mathrm{C}$ ), the seedlings were grown in wooden boxes $(42 \times 30 \times 18 \mathrm{~cm})$ in a 2:1:1 (volume) mixture of garden soil, humus and sand, respectively, for 21 days in a growth chamber (Controlled Env. Ltd., Winnipeg, Canada) at a $20 / 17^{\circ} \mathrm{C}$ day/night temperature and $75 / 70 \%$ relative humidity with $16 \mathrm{~h}$ illumination at $260 \mu \mathrm{mol} \mathrm{m} \mathrm{m}^{-2} \mathrm{~s}^{-1}$. The cold treatment was performed at $3^{\circ} \mathrm{C}$ until the appearance of the spike primordia without changing the other growth conditions. Sampling was performed at the end of the growth at $20 / 17^{\circ} \mathrm{C}$, after 10 or 14 days at $3^{\circ} \mathrm{C}$ (the apex was still in the vegetative phase), at the double ridge stage (Dr) of the apex (start of vegetative/generative transition) and after the appearance of the spikelet primordia $(\mathrm{Sp})$.

\section{Genotyping of the mvp mutant plants}

Leaf samples of $100 \mathrm{mg}$ were collected from the Tm and mvp mutant lines and smashed by TissueLyser (Qiagen) (shaking settings: $25 \mathrm{~Hz}, 1 \mathrm{~min}$ and $30 \mathrm{sec}$ ). The total DNA was isolated from crushed material by the ZenoGene ${ }^{40}$ DNA isolation kit (Zenon Bio Ltd.) and eluted in the last step in $200 \mu \mathrm{l}$ of elution buffer. A total of $2 \mu \mathrm{l}$ of DNA extract was used in the PCR experiments with the VRN1-specific primers VRN1-F: 5'-ACAAGAAAAACACTTGCAGAGAAGTTCAGC-3' and VRN1-R: 5'CATGGTAAATTACTCGTACAGCCATCTCAGC-3'.

These primers amplify a 1084-bp fragment of the VRN1 gene that is not present in the homozygous mutant. The PCR conditions were as follows: 40 cycle of $94^{\circ} \mathrm{C}$ for 20 sec, $61^{\circ} \mathrm{C}$ for $30 \mathrm{sec}$, and $72^{\circ} \mathrm{C}$ for $1 \mathrm{~min}$ and $20 \mathrm{sec}$. In the case of doubtful samples, the method of Dhillon et al. [10] was used with slight modifications in the final concentration of primers, i.e., $0.4 \mu \mathrm{M}$ MVP_F18, 0.3 $\mu \mathrm{M}$ MVP_R22 and $0.2 \mu \mathrm{M}$ MVP_R23 (MVP_F-18: 5' AGCCACAAGAACCGGGACTA-3', MVP_R-22: 5' -A TTCAAGCCCCAATGTTCTC-3' ${ }^{\prime}$, and MVP_R-23: 5' CCCAAACTTTGCGGTGTATC-3').

\section{Quantitative RT-PCR (qRT-PCR)}

Total RNA was isolated using the Direct-zol ${ }^{\mathrm{m}}$ RNA Miniprep Kit (Zymo Research) as described by the manufacturer. Reverse transcription was carried out with M-MLV reverse transcriptase and Oligo $(\mathrm{dT})_{18}$ primer (Thermo Scientific) using the method of the supplier. The transcript levels were determined with real-time RT-PCR using a CFX96 Touch ${ }^{\text {Tx }}$ Real-Time PCR Detection System (Bio-Rad). The phosphogluconate dehydrogenase Ta30797 served as a reference gene [50]. Primers used for detection of WCS19, COR14b and P5CS expression were described in $[10,27,28]$.

\section{Extraction and GC-MS analysis of the polar metabolites from wheat}

The shoot and crown samples were ground into a fine powder in liquid nitrogen. An extraction was performed according to Schauer et al. [51] using $100 \mathrm{mg}$ of tissue 
powder. Ribitol was added to the samples as an internal standard. An aliquot of $150 \mu \mathrm{l}$ of extract was dried with 30 $\mu \mathrm{l}$ of ribitol $\left(20 \mathrm{mg} \mathrm{ml}^{-1}\right)$. For methoxyamination, $40 \mu \mathrm{l}$ of methoxyamine hydrochloride (MEOX) that was dissolved at $20 \mathrm{mg} \mathrm{ml}^{-1}$ in pyridine was added to the dried extract and agitated for $90 \mathrm{~min}$ at $37^{\circ} \mathrm{C}$. N-methyl-N-(trimethylsilyl) trifluoroacetamide (MSTFA) was used for the derivatisation $\left(60 \mu \mathrm{l}, 30 \mathrm{~min}\right.$, and $\left.37^{\circ} \mathrm{C}\right)$. The samples were analysed in the split mode in a quadrupole-type GCMS system (Finnigan Trace/DSQ, Thermo Electron Corp., Austin, TX, USA) that was equipped with a 30m capillary column (Rxi-5 ms, 0.25 mm ID, $0.25 \mu \mathrm{m}$ df, Restek, Bellefonte, PA, USA). For GC-MS detection, an electron ionization system with ionization energy of $70 \mathrm{eV}$ was used. Sample volumes of $1 \mu$ l were injected with a split ratio of $10 \mathrm{ml} \mathrm{min}{ }^{-1}$ using the hot needle technique. The injection temperature was $230^{\circ} \mathrm{C}$, and the temperatures of the interface and the ion source were set to $250^{\circ} \mathrm{C}$. The carrier gas was helium, with a constant flow rate of $1 \mathrm{ml} \mathrm{min}-1$. The temperature program was heating at $90^{\circ} \mathrm{C}$ for $2 \mathrm{~min}$, followed by a $25^{\circ} \mathrm{C}$ $\min ^{-1}$ oven temperature ramp to $165^{\circ} \mathrm{C}$ for $15 \mathrm{~min}$. This ramp was followed by $6^{\circ} \mathrm{C} \mathrm{min}^{-1}$ to $330^{\circ} \mathrm{C}$. The system was temperature-equilibrated for $2 \mathrm{~min}$ at $90^{\circ} \mathrm{C}$ prior to injection of the next sample. The detection was performed in total ion chromatogram (TIC) positive mode. Mass

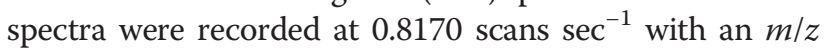
50-650 scanning range.

\section{Data analysis}

The Thermo Scientific Xcalibur software was used for exporting the spectra and searching the NIST 11 mass spectral database. The NIST 11 is a fully evaluated collection of electron ionisation and mass spectra, with chemical and GC data, plus search software to identify the own unknown spectra. In addition, the sugars and amino acids were identified based on a comparison of the retention time and mass spectrum to an authentic standard that was analysed under identical conditions. A one-way MANOVA using the SPSS software package (SPSS Inc., an IBM Company) was used to determine whether there were significant differences between the metabolite compositions of independent groups of samples. For statistical analysis R (version 3.0.2) was used (http://www.r-project.org). Pairwise comparisons were performed using custom $\mathrm{R}$ scripts. Pearson correlation coefficients were calculated using R's built-in function cor. Student's $t$-test was used to determine significant differences in gene expression at $P<0.01$.

\section{Availability of supporting data}

The datasets supporting the results of this study are included within the article and its additional files.

\section{Additional files}

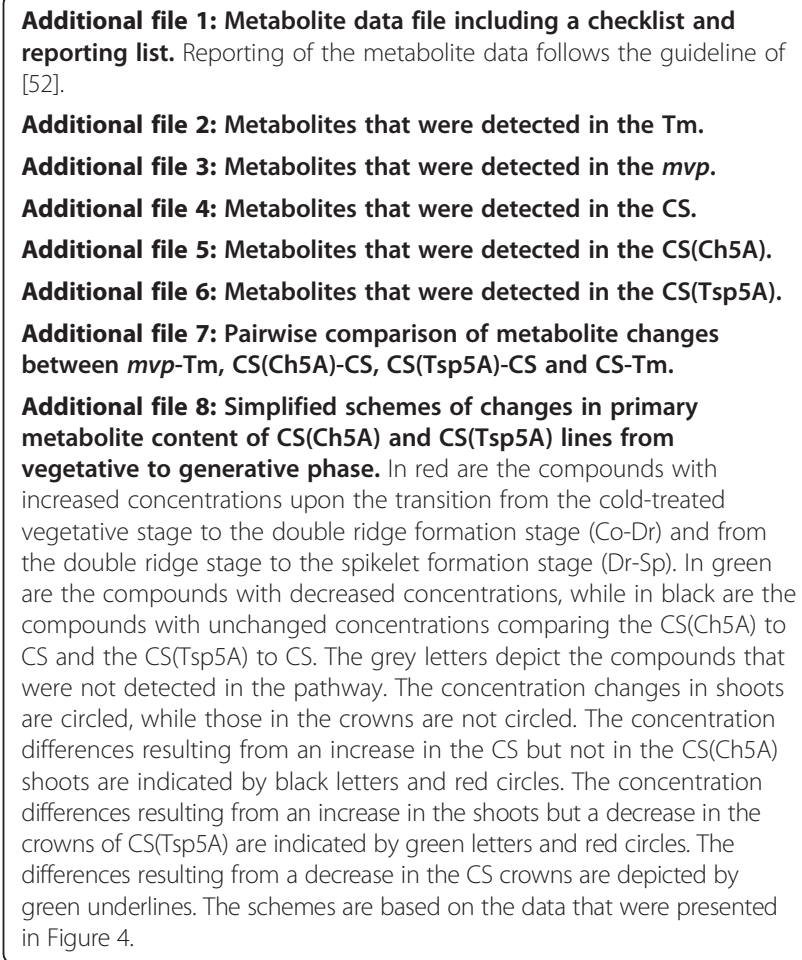

\section{Abbreviations}

C: Control; Ch5A: Cheyenne chromosome 5A; Co: Cold-treated during the vegetative phase; CS: Chinese spring; Dr: Double ridge formation; GC-MS: Gas chromatography-mass spectrometry; Sp: Spikelet formation; Tm: Triticum monococcum; Tsp5A: Triticum spelta chromosome 5A; VRN: MADS-box transcription factor regulating the vernalisation process; mvp: Maintained vegetative phase.

\section{Competing interests}

The authors declare that they have no competing interests.

\section{Authors' contributions}

ZJ processed the samples for metabolite profiling and conducted the GC-MS and a part of the statistical analysis. ÁB collected the samples and PCR-tested the plants. TN contributed to the statistical analysis and heat-mapping. GK supervised $A ́ B$ and helped run the experiments. FM helped in the data analysis and heat-mapping. GG conceived and coordinated the project together with ZB. The body of the paper was written by ZB. All of the authors received, edited and approved the final version of the manuscript.

\section{Acknowledgements}

We thank Monika Kiss for excellent technical assistance. This work was supported by the Hungarian Scientific Research Fund (OTKA CNK80781, CNK80936).

\section{Author details}

${ }^{1}$ NARIC Agricultural Biotechnology Institute, Szent-Györgyi A. u. 4, 2100 Gödöllő, Hungary. ${ }^{2}$ Department of Plant Molecular Biology, Agricultural Institute, Centre for Agricultural Research, Hungarian Academy of Sciences, Brunszvik u. 2, 2462 Martonvásár, Hungary. ${ }^{3}$ Doctoral School of Animal and Agricultural Environmental Sciences, Department of Plant Sciences and Biotechnology, University of Pannonia Georgikon Faculty, Deák Ferenc u. 16, 8360 Keszthely, Hungary. 
Received: 29 May 2014 Accepted: 2 December 2014

Published online: 19 February 2015

\section{References}

1. Petersen G, Seberg O, Yde M, Berthelsen K: Phylogenetic relationships of Triticum and Aegilops and evidence for the origin of the A, B, and D genomes of common wheat (Triticum aestivum). Mol Phylogenet Evol 2006, 39:70-82.

2. Galiba G, Vágújfalvi A, Li C, Soltész A, Dubcovsky J: Regulatory genes involved in the determination of frost tolerance in temperate cereals. Plant Sci 2009, 176:12-19.

3. Trevaskis B, Hemming MN, Dennis ES, Peacock WJ: The molecular basis of vernalization-induced flowering in cereals. Trends Plant Sci 2007, 12:352-357.

4. Distelfeld A, Li C, Dubcovsky J: Regulation of flowering in temperate cereals. Curr Opin Plant Biol 2009, 12:178-184.

5. Greenup A, Peacock WJ, Dennis ES, Trevaskis B: The molecular biology of seasonal flowering-responses in Arabidopsis and the cereals. Ann Bot 2009, 103:1165-1172.

6. Fowler DB, Chauvin LP, Limin AE, Sarhan F: The regulatory role of vernalization in the expression of low-temperature-induced genes in wheat and rye. Theor Appl Genet 1996, 93:554-559.

7. Fowler DB, Limin AE, Wang S-Y, Ward RW: Relationship between lowtemperature tolerance and vernalization response in wheat and rye. Can J Plant Sci 1996, 76:37-42.

8. Fowler DB, Limin AE: Interactions among factors regulating phenological development and acclimation rate determine low-temperature tolerance in wheat. Ann Bot 2004, 94:717-724.

9. Danyluk J, Kane NA, Breton G, Limin AE, Fowler DB, Sarhan F: TaVRT-1, a putative transcription factor associated with vegetative to reproductive transition in cereals. Plant Physiol 2003, 132:1849-1860.

10. Dhillon T, Pearce SP, Stockinger EJ, Distelfeld A, Li C, Knox AK, Vashegyi I, Vágúffalvi $A$, Galiba G, Dubcovsky J: Regulation of freezing tolerance and flowering in temperate cereals: the VRN-1 connection. Plant Physiol 2010, 153:1846-1858.

11. Heun M: Site of Einkorn Wheat Domestication Identified by DNA Fingerprinting. Science (80-) 1997, 278:1312-1314.

12. Shitsukawa N, Ikari C, Shimada S, Kitagawa S, Sakamoto K, Saito H, Ryuto H, Fukunishi N, Abe T, Takumi S, Nasuda S, Murai K: The einkorn wheat (Triticum monococcum) mutant, maintained vegetative phase, is caused by a deletion in the VRN1 gene. Genes Genet Syst 2007, 82:167-170.

13. Sears AER, The S, Naturalist A, Aug NJ: Nullisomic Analysis in Common Wheat. Am Nat 1953, 87:245-252.

14. Pugsley A: A genetic analysis of the spring-winter habit of growth in wheat. Aust J Agric Res 1971, 22:21-31.

15. Snape JW, Law CN, Worland AJ: Chromosome variation for loci controlling ear emergence time on chromosome 5A of wheat. Heredity (Edinb) 1976, 37:335-340.

16. Law CN, Worland AJ, Giorgi B: The genetic control of ear-emergence time by chromosomes 5A and 5D of wheat. Heredity (Edinb) 1976, 36:49-58.

17. Chen Y, Carver BF, Wang S, Zhang F, Yan L: Genetic loci associated with stem elongation and winter dormancy release in wheat. Theor Appl Genet 2009, 118:881-889.

18. Eagles HA, Cane K, Trevaskis B: Veery wheats carry an allele of Vrn-A1 that has implications for freezing tolerance in winter wheats. Plant Breed 2011, 130:413-418.

19. Miller AK, Galiba G, Dubcovsky J: A cluster of 11 CBF transcription factors is located at the frost tolerance locus $F r-A^{\mathrm{m}} 2$ in Triticum monococcum. Mol Genet Genomics 2006, 275:193-203.

20. Vágúffalvi A, Aprile A, Miller A, Dubcovsky J, Delugu G, Galiba G, Cattivelli L: The expression of several $C b f$ genes at the Fr-A2 locus is linked to frost resistance in wheat. Mol Genet Genomics 2005, 274:506-514.

21. Vágújfalvi A, Kerepesi I, Galiba G, Tischner T, Sutka J: Frost hardiness depending on carbohydrate changes during cold acclimation in wheat. Plant Sci 1999, 144:85-92.

22. Galiba G, Simon-Sarkadi L, Kocsy G, Salgo A, Sutka J: Possible chromosomal location of genes determining the osmoregulation of wheat. Theor Appl Genet 1992, 85:415-418.

23. Galiba G, Kocsy G, Kaur-Sawhney R, Sutka J, Galston AW: Chromosomal localization of osmotic and salt stress-induced differential alterations in polyamine content in wheat. Plant Sci 1993, 92:203-211.
24. Kocsy G, Athmer B, Perovic D, Himmelbach A, Szucs A, Vashegyi I, Schweizer P, Galiba G, Stein N: Regulation of gene expression by chromosome 5A during cold hardening in wheat. Mol Genet Genomics 2010, 283:351-363.

25. Obata T, Fernie AR: The use of metabolomics to dissect plant responses to abiotic stresses. Cell Mol Life Sci 2012, 69:3225-3243.

26. Ganeshan S, Vitamvas P, Fowler DB, Chibbar RN: Quantitative expression analysis of selected COR genes reveals their differential expression in leaf and crown tissues of wheat (Triticum aestivum L.) during an extended low temperature acclimation regimen. J Exp Bot 2008, 59:2393-2402.

27. Campoli C, Matus-Cádiz MA, Pozniak CJ, Cattivelli L, Fowler DB: Comparative expression of $\mathrm{Cbf}$ genes in the Triticeae under different acclimation induction temperatures. Mol Genet Genomics 2009, 282:141-152.

28. Dong J1, Bowra S, Vincze E: The development and evaluation of single cell suspension from wheat and barley as a model system; a first step towards functional genomics application. BMC Plant Biol 2010, 10:239.

29. Diallo AO, Agharbaoui Z, Badawi MA, Ali-Benali MA, Moheb A, Houde M, Sarhan F: Transcriptome analysis of an mvp mutant reveals important changes in global gene expression and a role for methyl jasmonate in vernalization and flowering in wheat. J Exp Bot 2014, 65:2271-2286.

30. Guy C, Kaplan F, Kopka J, Selbig J, Hincha DK: Metabolomics of temperature stress. Physiol Plant 2008, 132:220-235.

31. Hayat S, Hayat Q, Alyemeni MN, Wani AS, Pichtel J, Ahmad A: Role of proline under changing environments: a review. Plant Signal Behav 2012, 7:1456-1466,

32. Lee YP, Babakov A, de Boer B, Zuther E, Hincha DK: Comparison of freezing tolerance, compatible solutes and polyamines in geographically diverse collections of Thellungiella sp. and Arabidopsis thaliana accessions. BMC Plant Biol 2012, 12:131.

33. Colton-Gagnon K, Ali-Benali MA, Mayer BF, Dionne R, Bertrand A, Do Carmo S, Charron J-B: Comparative analysis of the cold acclimation and freezing tolerance capacities of seven diploid Brachypodium distachyon accessions. Ann Bot 2014, 113:681-693.

34. Kamata T, Uemura M: Solute accumulation in wheat seedlings during cold acclimation: contribution to increased freezing tolerance. CryoLetters 2004, 25:311-322.

35. Yoshida M, Abe J, Moriyama M, Kuwabara T: Carbohydrate levels among winter wheat cultivars varying in freezing tolerance and snow mold resistance during autumn and winter. Physiol Plant 1998, 103:8-16.

36. Olien CR, Clark JL: Changes in Soluble Carbohydrate Composition of Barley, Wheat, and Rye during Winter. Agron J 1993, 85:21.

37. Hurry VM, Strand A, Tobiaeson M, Gardestrom P, Oquist G: Cold hardening of spring and winter wheat and rape results in differential effects on growth, carbon metabolism, and carbohydrate content. Plant Physiol 1995, 109:697-706.

38. Roitsch T, Balibrea ME, Hofmann M, Proels R, Sinha AK: Extracellular invertase: key metabolic enzyme and PR protein. J Exp Bot 2003, 54:513-524.

39. Kobayashi S, Nagasawa S, Yamamoto Y, Donghyo K, Bamba T, Fukusaki E: Metabolic profiling and identification of the genetic varieties and agricultural origin of Cnidium officinale and Ligusticum chuanxiong. J Biosci Bioeng 2012, 114:86-91.

40. $\mathrm{Xu} Y, \mathrm{Du} \mathrm{H}$, Huang B: Identification of metabolites associated with superior heat tolerance in thermal bentgrass through metabolic profiling. Crop Sci 2013, 53:1626-1635.

41. Yun Z, Gao H, Liu P, Liu S, Luo T, Jin S, Xu Q, Xu J, Cheng Y, Deng X: Comparative proteomic and metabolomic profiling of citrus fruit with enhancement of disease resistance by postharvest heat treatment. BMC Plant Biol 2013, 13:44.

42. Wu D, Cai S, Chen M, Ye L, Chen Z, Zhang H, Dai F, Wu F, Zhang G: Tissue metabolic responses to salt stress in wild and cultivated barley. PLoS One 2013, 8:e55431.

43. Wu D, Shen Q, Cai S, Chen Z-H, Dai F, Zhang G: lonomic responses and correlations between elements and metabolites under salt stress in wild and cultivated barley. Plant Cell Physiol 2013, 54:1976-1988.

44. Distelfeld A, Dubcovsky J: Characterization of the maintained vegetative phase deletions from diploid wheat and their effect on VRN2 and FT transcript levels. Mol Genet Genomics 2010, 283:223-232.

45. Chen TH, Gusta LV, Fowler B: Freezing injury and root development in winter cereals. Plant Physiol, 1983, 73:773-777.

46. Winfield MO, Lu C, Wilson ID, Coghill JA, Edwards KJ: Plant responses to cold: transcriptome analysis of wheat. Plant Biotechnol J 2010, 8:749-771. 
47. Cahalan C, Law CN: The genetical control of cold resistance and vernalisation requirement in wheat. Heredity (Edinb) 1979, 42:125-132.

48. Sutka J: Genetic studies of frost resistance in wheat. Theor Appl Genet 1981, 59:145-152.

49. Veisz O, Sutka J: The relationships of hardening period and the expression of frost resistance in chromosome substitution lines of wheat. Euphytica 1989, 43:41-45.

50. Paolacci AR, Tanzarella OA, Porceddu E, Ciaffi M: Identification and validation of reference genes for quantitative RT-PCR normalization in wheat. BMC Mol Biol 2009, 10:11.

51. Schauer N, Zamir D, Fernie AR: Metabolic profiling of leaves and fruit of wild species tomato: a survey of the Solanum lycopersicum complex. J Exp Bot 2005, 56:297-307.

52. Fernie AR, Aharoni A, Willmitzer L, Stitt M, Tohge T, Kopka J, Carroll AJ, Saito $\mathrm{K}$, Fraser PD, DeLuca V: Recommendations for reporting metabolite data. Plant Cell 2011, 23:2477-2482.

\section{Submit your next manuscript to BioMed Central and take full advantage of:}

- Convenient online submission

- Thorough peer review

- No space constraints or color figure charges

- Immediate publication on acceptance

- Inclusion in PubMed, CAS, Scopus and Google Scholar

- Research which is freely available for redistribution 